\title{
Urban form, infrastructure and spatial organisation in the Roman Empire
}

John W. Hanson ${ }^{1, *}$, Scott G. Ortman ${ }^{2}$, Luís M.A. Bettencourt ${ }^{3}$ $\&$ Liam C. Mazur ${ }^{3}$

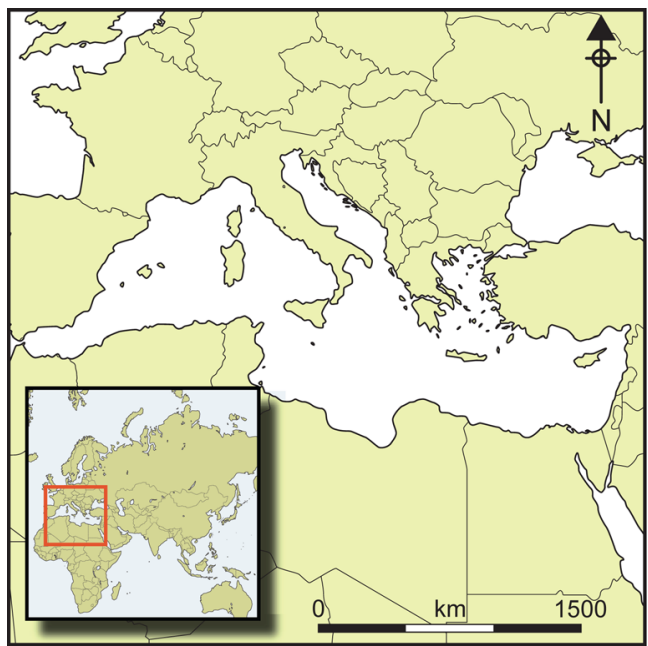

Although there has been considerable scholarly interest in the nature of ancient cities, it has been difficult to identify and explore quantitative patterns in their design and amenities. Here, the authors offer a model for the relationship between the population size and infrastructural area of settlements, before testing it against measures of urban form in the Roman Empire. They advocate a more consistent approach to the investigation of settlements that is capable of not only incorporating sites with divergent physical forms and historical trajectories into the same model, but also able to expose their similarities and differences.

Keywords: Roman Empire, urbanism, settlement-scaling theory, built environment

\section{Introduction}

The dimensions of the forum should be based on the population; its area should neither be too cramped for efficiency nor so large that for lack of population it looks deserted. Vitruvius (Ten Books on Architecture V.1.2; Rowland \& Howe 1999)

Over the last decade, a new field of enquiry into urban form has developed around the testing of formal models against the vast quantities of cross-sectional data now available for contemporary cities (Fujita et al. 2001; Batty 2013). Topics of interest include the spatial distribution of urban activities, the design of street networks and the mechanisms behind the formation and evolution of cities. This research has suggested various techniques for investigating urban form, ranging from simple quantification to sophisticated network analyses

1 Department of Classics, University of Reading, Reading RG6 6BT, UK

2 Department of Anthropology, University of Colorado, Boulder, CO 80309, USA

3 Mansueto Institute for Urban Innovation, University of Chicago, Chicago IL 60637, USA

* Author for correspondence (Email: j.w.hanson@reading.ac.uk)

(C) Antiquity Publications Ltd, 2019. This is an Open Access article, distributed under the terms of the Creative Commons Attribution licence (http://creativecommons.org/licenses/by/4.0/), which permits unrestricted re-use, distribution, and reproduction in any medium, provided the original work is properly cited.

ANTIQUITY 93369 (2019): 702-718

https://doi.org/10.15184/aqy.2018.192 
(Strano et al. 2012; Louf \& Barthelemy 2014). These studies have sought to classify cities according to aspects of their design and amenities, with a view to explaining their distinct spatial forms and the mechanisms influencing their development and deterioration.

Concurrently, there has been significant discussion among classical archaeologists and ancient historians about the nature of Greek and Roman cities. These debates have revolved around the issue of whether urban centres were designed or reshaped according to a standard template centred on public spaces such as fora and agorae, with a common set of monuments articulated by street grids (Smith 2007; Laurence et al. 2011; Zuiderhoek 2016). Recent work on ancient urbanism shows that there was not only considerable variation in the design of cities and the provision of amenities, but also that they responded to the advent of imperial rule in different ways (Hanson 2016). Although some were originally laid out on grids, most expanded in an organic fashion. In addition, although some cities were provisioned with specific structures from the outset, most acquired these suites of buildings over time-depending on their individual social, political and economic situations. Although the largest cities, such as Rome, did have both the highest number and greatest diversity of monuments, there is no evidence for any strict relationship between city size and the occurrence of specific structures (Hanson 2016: tabs $22 \& 25$ ).

This state of affairs raises the question of what organisational logic, if any, lay behind the urban form of ancient cities and how the variation among them might be meaningfully explored. Here, we use an emerging framework known as settlement-scaling theory to organise some of the data available for the built environments of Roman cities. Drawing on both recent theoretical work on complex systems and recent empirical research on urbanism in a range of contexts, this framework suggests that there is, in fact, a consistent set of relationships between the population of settlements and various aspects of the built environment (Bettencourt et al. 2007; Bettencourt \& West 2010; Bettencourt 2013; Ortman et al. 2014). The framework also offers a new way of thinking about the design of and the amenities at ancient settlements, which may allow us to clarify the similarities and differences between settlements and to explore the reasons for their divergent forms and development. We use this framework here to clarify and reappraise the relationships between city size and urban form.

\section{Aims and objectives}

We offer a new model of the relationship between the population size and social infrastructure of settlements, where we conceive of settlements as containers within which individuals interact. This allows us to evaluate how the space needed for these interactions expands as the number of individuals involved increases. We then test the applicability of this model for ancient urbanism by drawing on a recent catalogue of Roman cities to estimate the size of their urban populations (Hanson 2016). We concentrate on one of the most basic measures of settlement infrastructure - the space set aside for individuals to interact and move around the built environment-focusing on three measures of urban form: the sizes of fora and agorae, the lengths and widths of street networks and the shapes of city blocks. We then analyse the relationship between these measures and settlement size to assess the extent to which they conform to relationships observed in modern cities. We conclude by arguing that this approach can be used to isolate some of the organisational logic of ancient settlements,

(C) Antiquity Publications Ltd, 2019 
with a view to establishing new avenues for more detailed research into their individual contexts and specific characteristics.

\section{Theoretical background}

Our approach is based on a conception of settlements as social networks embedded in the built environment, in which individuals arrange themselves so as to balance the benefits of interaction with the costs of movement (Bettencourt 2013; Ortman et al. 2014). This approach follows on from recent research, which demonstrates that, generally, as the number of residents increases, the population density of a settlement also increases. This leads not only to relative efficiencies in the use of infrastructure (i.e. increasing economies of scale), but also to a magnification of various socio-economic rates measured in per capita terms (i.e. increasing returns to scale). These effects can be explained as a consequence of greater contact between individuals; as urban populations grow, the opportunities for individuals to interact, to share resources and to exchange knowledge, skills and ideas also increase.

Although this framework was originally developed in relation to modern cities, subsequent research has shown that it is also applicable to historical and archaeological settlements, including those of Roman and medieval Europe (Bettencourt 2013; Cesaretti et al. 2016; Hanson \& Ortman 2017; Hanson et al. 2017). The present article, however, is the first attempt to identify economies of scale in the infrastructure of ancient cities through the investigation of the built environment, although there has been interest in doing so for some time (Hanson 2016; Mandich 2016).

At its most basic, settlement-scaling theory is a formal quantitative framework that proposes how a variety of aggregate properties of settlements change as their populations increase. As a result, we can predict the average relationship between the scale of infrastructure and the resident population by considering the amount of space required within a settlement to facilitate various forms of social mixing, and how this space changes as the number of residents increases. An important feature of recent theoretical and empirical work, however, is that the space required for interaction does not increase at the same rate as settlement population; instead, it becomes more condensed on a per capita basis (Bettencourt 2013; Ortman et al. 2014).

This can be conceptualised by considering the amount of space required for a community of a certain size to interact in pursuit of their daily needs. A key assumption is that a consistent proportion of the population will need to mix on a regular basis for the settlement to exist as a socio-economic entity. While this group could be limited to adults, it could also include a much larger cross-section of the population, as the motivation for interaction is not restricted to a narrow range of activities. In either case, one would expect the arrangement of individuals within these interaction spaces to reflect a balance between the costs of moving around the space and the net benefits of interacting with others. This balance emerges from the aggregation of numerous actions across space and time, integrated over the physical movements of each individual and how their paths overlap with those of others. This idea can be quantified relatively simply, and provides a basis for calculating the relationship between population and spaces for mixing.

(C) Antiquity Publications Ltd, 2019 
As explained in more detail in the online supplementary material (OSM), we can model this network of interactions based on the concept of a spatial (short-term) equilibrium-a fundamental concept in urban geography (Fujita et al. 2001). Although it is possible to devise more detailed models than the one used here, it is sufficient for our purposes to work with average quantities to derive expected relationships. When we equate the costs and benefits of interactions, the model predicts that the total area needed for interactions should grow more slowly than the population of the settlement, with an exponent (i.e. slope) of approximately two-thirds. The same logic can be used to conceptualise how settlement area is threaded by public spaces and street networks, treating them as access networks. This model represents an initial approximation, as it does not take into account the specific arrangement of space within a settlement and the additional constraints resulting from these different configurations. Nevertheless, the model leads to an expected relationship between the sizes of sites and the average lengths and widths of streets per capita. This suggests that the spatial extent of settlements expands more slowly than the area taken up by their street networks-with an exponent of about two-thirds for their average area and approximately one-half and one-sixth for their average lengths and widths respectively.

As demonstrated below, these relationships allow us to analyse the empirical findings for a range of variables that characterise ancient settlements, including their total built-up area, the sizes of fora and agorae, the dimensions of street networks and even some surprising aspects concerning the shapes of their city blocks. It is important to stress, however, that these models describe average conditions across settlements, rather than the specific situation in a particular settlement. One would expect the built environment of any individual settlement to be the result of many factors, contingent upon its unique geographic and historical context. Nevertheless, our models suggest that the population of a settlement is the most important factor conditioning the overall built environment, with other factors being reflected in the residual (i.e. deviation) of a given settlement from the overall scaling relationship between population and the amount of infrastructure. Although the claim that population should play such a determining role in the average quantities of settlements is bold, it is one that has robust empirical support from studies based on a wide variety of settlement systems, including both past and present, urban and non-urban (Angel et al. 2012; Bettencourt 2013; Cesaretti et al. 2016; Hanson \& Ortman 2017).

\section{Definitions, sites and estimated populations}

We concentrate on cities located across the region encompassed by the Roman Empire at its maximum extent in $\mathrm{AD} 117$, considering the period between the first century $\mathrm{BC}$ and the third century AD. To define urbanism, we follow the definition in Hanson's study of urbanism in the Roman Empire in the Imperial period (Hanson 2016). As he notes, although it is challenging to devise a single definition of urbanism that is acceptable to all scholars, we can suggest a working definition by concentrating on sites associated with non-subsistence activities, identified on the basis of their size, monuments and civic statuses. Although there are other definitions that could be used, this one has been widely employed by other scholars. Furthermore, this definition is linked to Hanson's catalogue of sites.

(C) Antiquity Publications Ltd, 2019 
To estimate the number of residents at these sites, we began by taking existing evidence for their inhabited areas, including the space enclosed by walls, the extent of urban grids, the size of residential zones, the location of cemeteries and the character of natural features, such as topographical relief, rivers and coastlines (Hanson 2016). We then used an equation from previous work, which is based on detailed evidence for the relationship between the inhabited area and housing density of more than 50 Greek and Roman sites, to estimate the populations of each settlement in our sample (Hanson \& Ortman 2017) (Figure 1).

\section{Urban form, infrastructure and spatial organisation}

To investigate the relationships discussed above, we focus on three interconnected measures of urban form: the sizes of fora and agorae, the dimensions of street networks and the shapes of city blocks. These features are ideal for testing the new models described above, as they all represent spaces used by individuals to interact on a day-to-day basis for a variety of purposes related to the life of the city. In particular, while fora and agorae can be seen as mixing spaces, street networks and city blocks can be regarded as an indication of the networks used to access these spaces. Hence, we can conceive of these features as a kind of infrastructure for the sorts of interaction that were central to the effective functioning of a city as a social and economic entity.

These features are also important because they provide a schematic view of settlements that characterises much of their structure and contains a great deal of information about the mechanisms behind their formation and evolution (Kostof 1991, 1992; Louf \& Barthelemy 2014). This is because features such as fora and streets are integral to the spatial organisation of settlements and for the overall dynamics of the activities that took place within them. This has effects at various scales, from an individual's access to resources through to the structure of land ownership and land values. These features also tend to be more stable than other elements of settlements, such as individual buildings, and tend to have a significant long-term influence on their development (Kostof 1991, 1992; Strano et al. 2012).

\section{Fora and agorae, street networks and blocks}

To measure these features, we have concentrated on mixing spaces - those elements of the built environment that facilitated the circulation of individuals. We have taken a functional approach that excludes ancillary spaces such as colonnades, shops and workshops, as these are associated with more specific activities. An additional advantage of this narrower approach is that fora and agorae are clearly delimited and detectable across sites from different regions and periods, and are comparable with spaces that have been studied in other contexts, including open spaces in modern cities and plazas in ancient settlements in the New World (Ossa et al. 2017). To compile the data, we identified those sites in the catalogue of Roman cities with the clearest evidence for fora and agorae, street networks and city blocks (Hanson 2016). We then used a combination of published maps and plans to measure the relevant features at each site using GIS (Ward-Perkins 1981; MacDonald 1986; Gros 1996).

Fora and agorae often take the form of an open space (fora tend to be rectangular, and agorae typically square), surrounded by colonnades and various buildings, such as temples,

(C) Antiquity Publications Ltd, 2019 


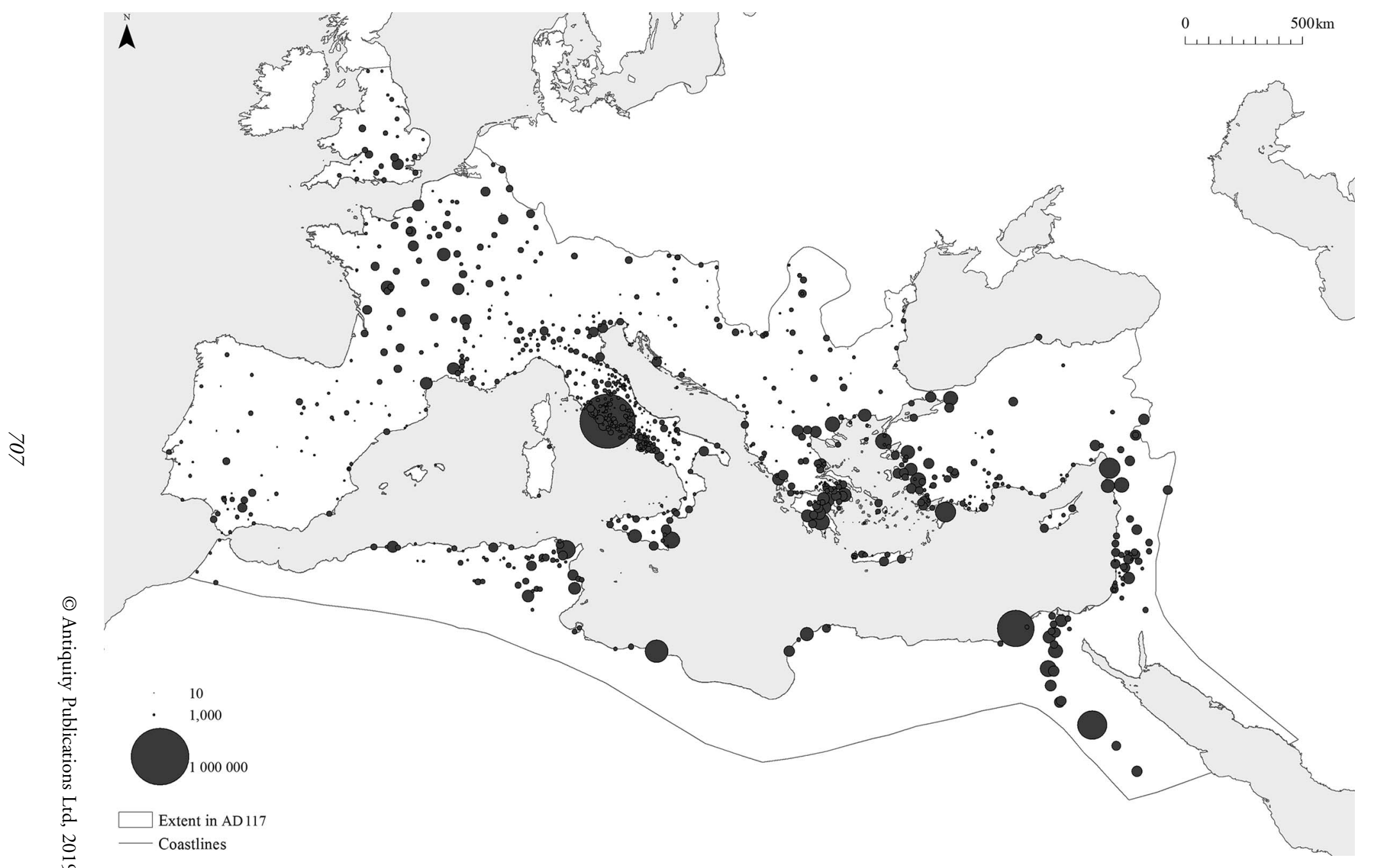

Figure 1. The estimated populations of cities in the Roman Empire (symbols are proportional to estimated population) (after Hanson \& Ortman 2017). 
offices, law courts, markets, shops and workshops. For each site, we measured the open area enclosed by the colonnades or surrounding buildings, omitting the roofed spaces covered by these colonnades and associated structures (Figure 2). We have generally restricted ourselves to sites for which we can trace a colonnade on all sides of the open space, or where we can follow the lines of associated structures, although there are some exceptions.

At Rome, we measured the sizes of the Forum Magnum and the imperial fora of Caesar, Augustus, Vespasian, Nerva and Trajan. While there are some differences of opinion concerning how these spaces should be reconstructed, these do not affect our measurements in a noticeable way. Due to their more organic development and less formal design, it is more challenging to estimate the size of Rome's commercial fora, including the Forum Boarium, Holitorium, Piscarium, Pistorium, Suarium and Vinarium, as well as others mentioned in textual and epigraphic sources. As a result, these features tend to be less well documented. We can, however, compensate to some extent by deriving rough estimates for some features based on Carandini's Atlas of ancient Rome (Carandini et al. 2017). Hence, our figure for the total amount of public space for the city of Rome may be a slight underestimate. These issues should not significantly affect the results, however, as the material under study behaves in an exponential fashion, and is surprisingly robust to measurement error, especially at the upper end of distributions (Ossa et al. 2017).

For Alexandria, we measured the approximate outline of the spaces indicated on a recent reconstruction of its urban grids (McKenzie 2007). For Ephesus, we included both the central and commercial agorae; for Pergamum, both the upper and lower agorae and the additional forum in the imperial extension; and for Smyrna, the rough outline of the central agora. We followed a similar approach for the other settlements, except for Aphrodisias, where we included only the area of the North Agora, as it has been recently suggested that the South Agora had a distinctive religious role (A.I. Wilson pers. comm.).

Although there are several ways of defining streets, we have identified them by using the segment of street between two intersections for simplicity (Louf \& Barthelemy 2014). We have then used the available evidence to identify individual city blocks, digitising their outlines and subtracting the outline of each block from the aggregate outline of all blocks; this produced a polygon representing the street network (Figure 3). Finally, we converted these polygons into centre-lines, allowing us to measure the lengths and widths of each street.

Unfortunately, we can only define the overall street network for a limited number of sites, as our method requires us to be able to reconstruct the entire site from either the remains of the ancient settlement or from the layout of the extant settlement on the same location. This issue is compounded by the fact that almost half of ancient settlements are still inhabited today. It is not, however, feasible to use a sample of each site, as we would expect the dimensions of street networks to have varied between the settlement's centre and its outskirts, due to a variety of factors. We have therefore restricted ourselves to the sites where we have complete, or nearly complete, knowledge of their street networks based on excavation, field-walking, geophysics or the morphology of the modern settlements that overlie their ancient predecessors. It should be noted, however, that it is not possible to reconstruct the complete outlines of any settlement in the ancient world in fine detail-especially in the case of the smallest backstreets. Nevertheless, we can assume that the missing sections of street networks are random across sites. Our data, therefore, should be adequate for assessing the average relationships between settlement populations and the measures of urban form discussed above.

(C) Antiquity Publications Ltd, 2019 


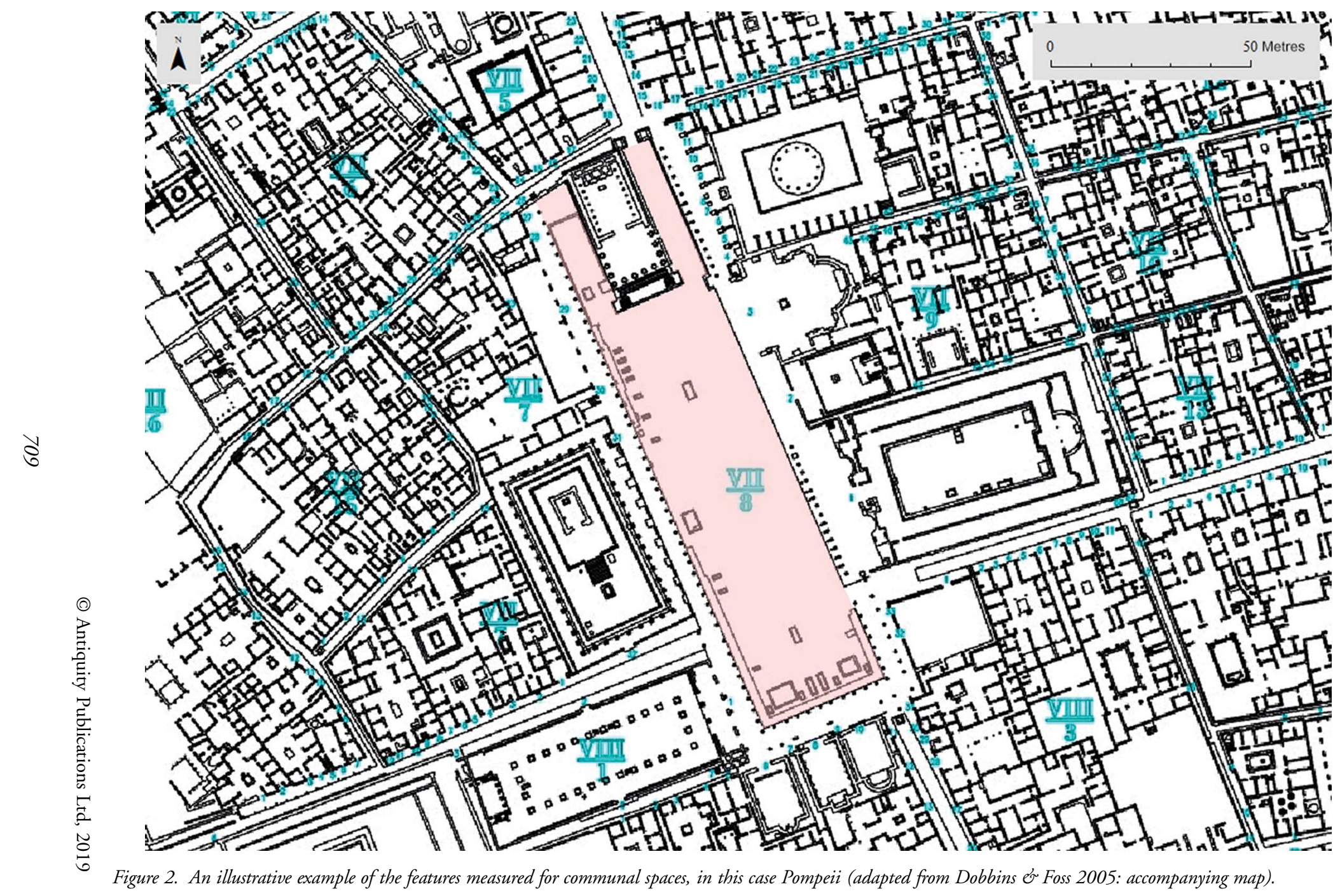

Research 


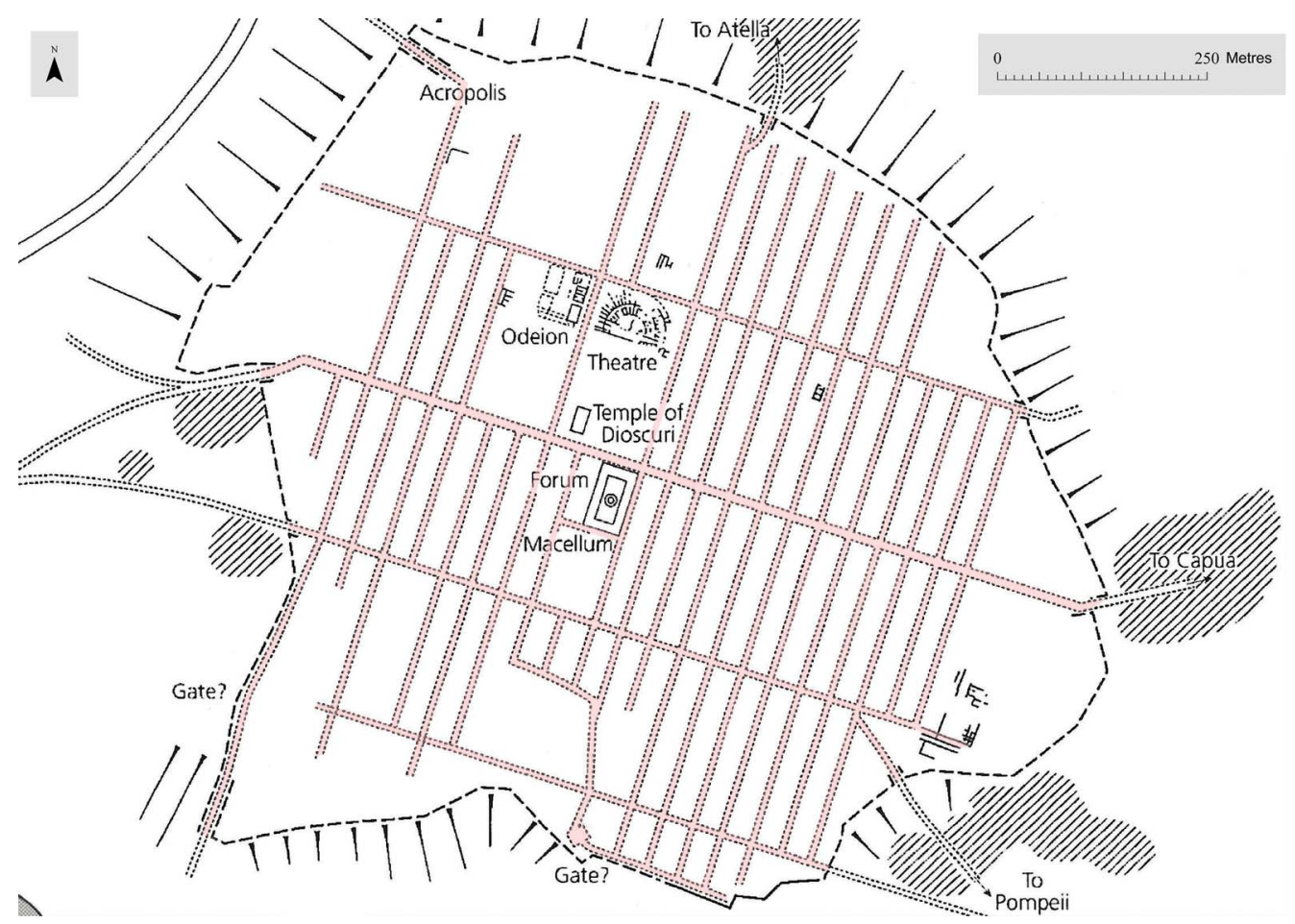

Figure 3. An illustrative example of the features measured for street networks, in this case Neapolis (Naples) (adapted from Laurence et al. 2011: fig. 5.1).

\section{Results}

We compiled data from 125 sites (Figure 4). This includes a core group for which we have measurements for both fora/agorae and street networks, along with groups of sites for which we only have measurements for one or the other. In total, we have estimates for fora and agorae in 80 sites, and street networks and blocks in 80 sites (with an overlap of 35 sites). The sample includes sites from across the settlement hierarchy (with estimated populations ranging from 458-923 406 inhabitants) distributed across the entire Mediterranean and its periphery, from the first century $\mathrm{BC}$ to the third century $\mathrm{AD}$. The sample includes both formally planned sites and those that developed organically; it also includes sites that have been extensively surveyed or excavated, and sites about which our knowledge is more limited.

We assess various relationships between population and the extent of infrastructure through ordinary least-squares regression (i.e. simple linear regression) of log-transformed estimates of population and measures of urban form. This is feasible because $y=b x^{m}$ and $\log y=m \log x+\log b$ are equivalent expressions, and therefore one can estimate the exponent and pre-factor of the power function through ordinary least-squares regression of the logtransformed values. The results show that there are indeed several strong relationships between the population of cities and the measures of urban form that we have investigated (Table 1). The results include estimates for the exponent of the relationship, which indicates (C) Antiquity Publications Ltd, 2019 


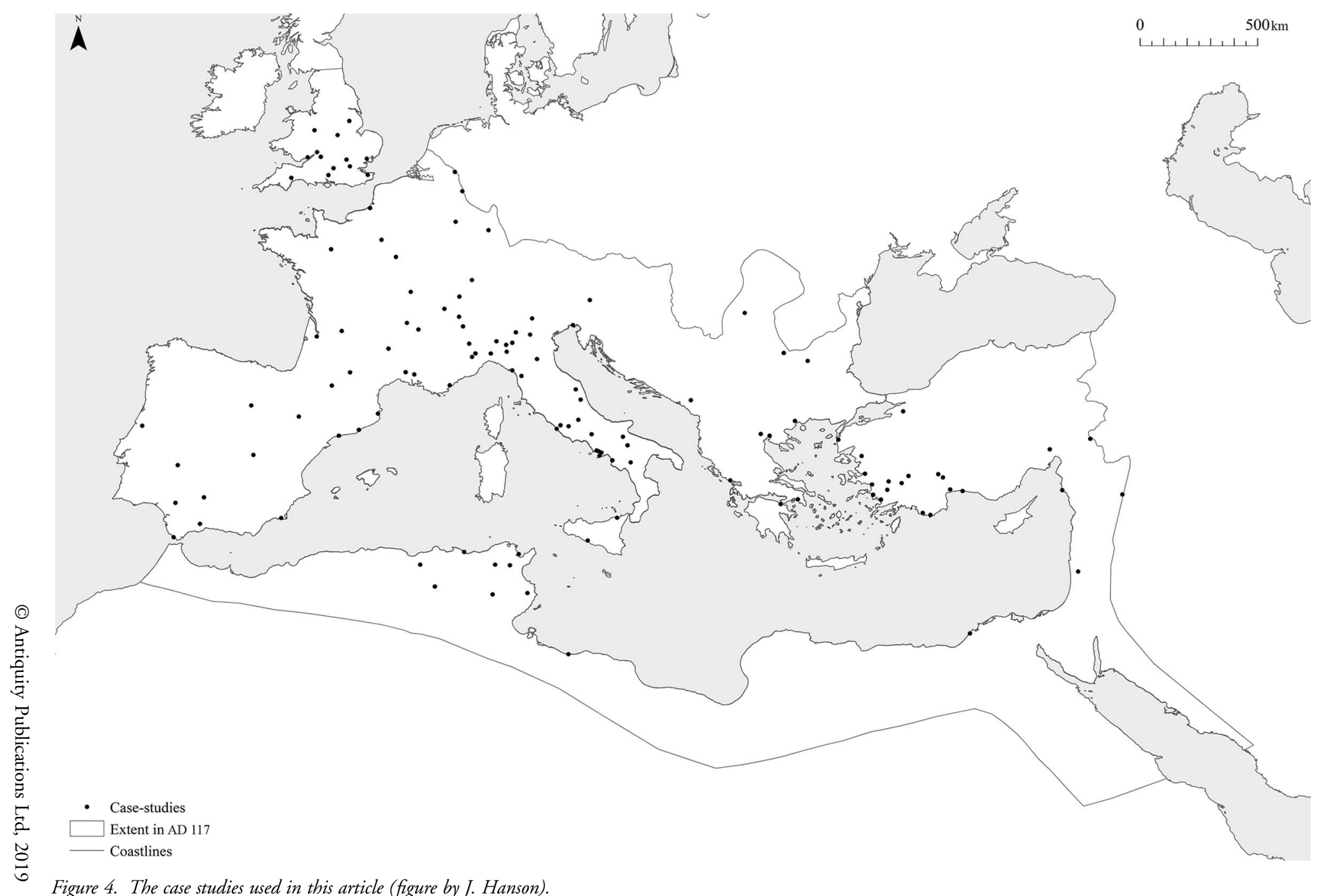

Figure 4. The case studies used in this article (figure by J. Hanson).

\section{Research}


the rate at which attributes change as the number of residents increases; and the pre-factor, which indicates the baseline amount of space that was allocated for each individual in the smallest settlements.

The results show that, on average, the total area of the street network increases with population raised to approximately the two-thirds power, the total street network length increases with population raised to the one-half power, and the average width of streets increases with population raised to the one-sixth power. This means, for example, that doubling the population leads to much less than twice the area of street network, with the lengths of streets growing faster than their average widths. These results also show that the minimal width of streets slightly exceeds $2 \mathrm{~m}$, which is consistent with a single-lane road designed to accommodate a fixed-axle wagon (Poehler 2017). This figure is also in keeping with the evidence for the widths of colonnaded streets recorded by other researchers (e.g. Burns 2017). In addition, the sizes of fora and agorae increase with population raised to approximately the two-thirds power, thus constituting an approximately fixed fraction of the built environment of each site. The baseline amount of space set aside for fora and agorae per person is almost $10 \mathrm{~m}^{2}$. The area of mixing space per person $A_{m} / N$ decreases with population to the $N^{2 / 3} /$ $N=N^{-1 / 3}$ power. These relationships are all consistent with the model in which a constant proportion of the built-up area was set aside for mixing spaces.

At face value, these results are in marked contrast with the typical pattern in modern cities, where street area is set aside in proportion to the area per resident. To make our results consistent with more recent evidence, we must introduce the idea that the average distance between people along the street network decreases as $\sim N^{-\frac{1}{6}}$. This could occur, for example, if an insufficient amount of space was incorporated in the form of side streets within blocks as the latter increased in size. Introducing this dependence to the expression for the length of streets leads to a predicted exponent of approximately one half for the population-street network length relation-given that total city area increases with an exponent of around two-thirds. In the same way, the expected exponent for the area of the street network declines from five-sixths to two-thirds, in accordance with our empirical observations. Together, these results predict the one-sixth exponent for the width of streets with population size, as factors of $\ell$ cancel out in the ratio $A_{n} / L_{n}$.

This effect seems to be a reflection of a unique adaptation in ancient cities. The fact that the average area of a city block scales with an exponent close to one-half suggests that if blocks occupy a fixed fraction of built-up space, then their total number should increase with an exponent of approximately one-sixth. This slow increase implies that the number of people per block increased quite quickly, with an exponent of about five-sixths. Therefore, even though blocks contained more people in larger cities, their population density still scales with an exponent of around one-third, as is the case for fora and agorae and street networks.

It is important to emphasise that these relationships are statistical averages across settlements, and that the specific relationship between population and infrastructure for any given city will deviate from this average. This variation around the mean is apparent in Figures 5 and 6, which display the data and the fit-line representing the average relationships between population $v$ s fora and agorae area, and population $v s$ street network area, respectively. The residual of each city to the fit-line captures the combined effect of measurement error and a myriad other factors

(C) Antiquity Publications Ltd, 2019 

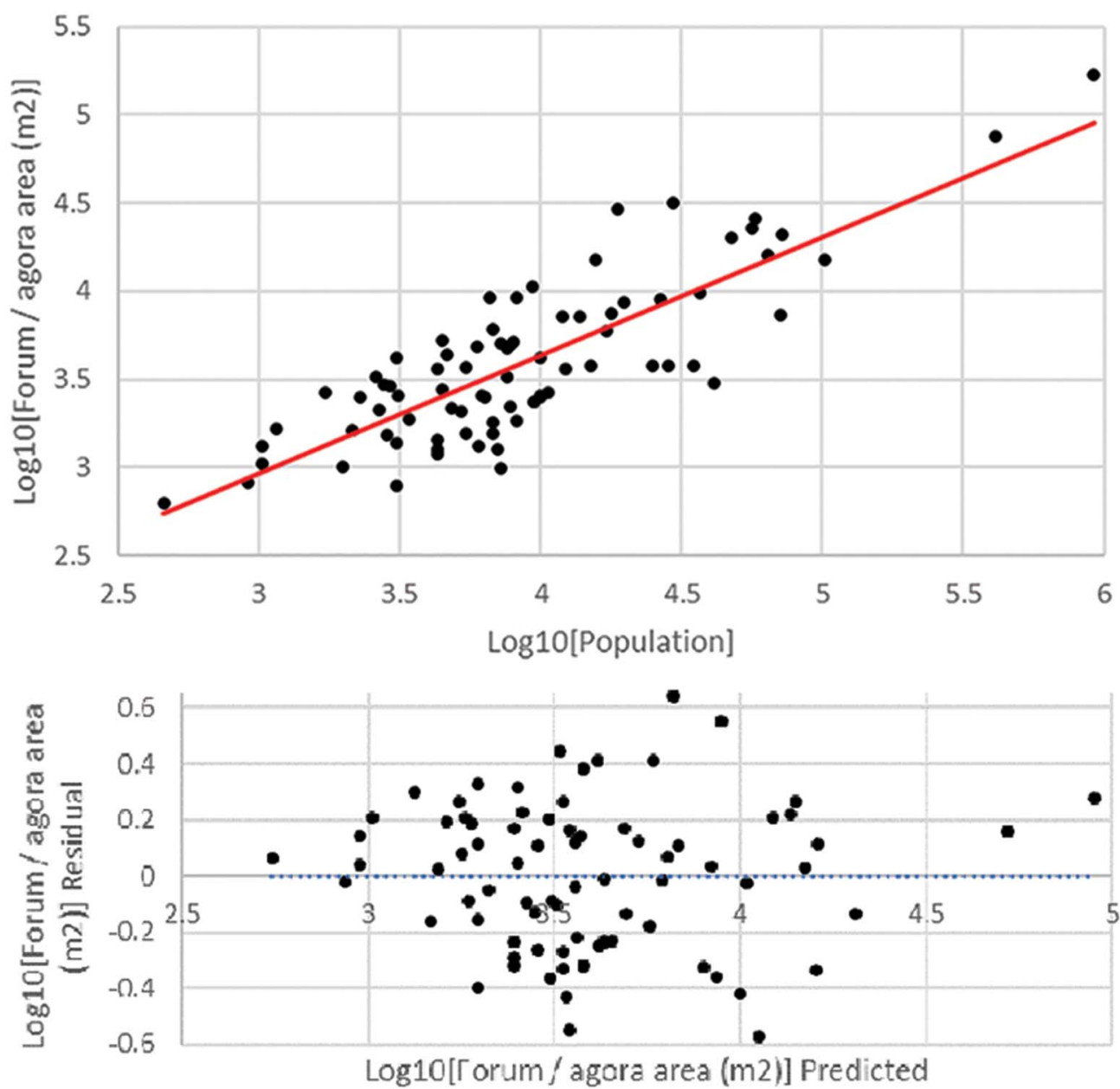

Figure 5. The relationship between population and communal area and the distribution of residuals from the fit-line; it is not possible to reject the null hypothesis that the residuals are normally distributed (Shapiro-Wilk $P=0.570$ ) (figure by J. Hanson).

not incorporated into the simple models presented earlier. It is notable, however, that around 70 per cent of the total variation in communal space and street network area is accounted for by the single variable, population (see the $\mathrm{R}^{2}$ values in Table 1), and that the residuals to the fit-line are normally distributed and non-heteroscedastic (i.e. not skewed) according to standard statistical tests (Figure 6). These results show that the number of residents is, in fact, a primary factor influencing the extent of infrastructure of ancient cities.

\section{Discussion}

These results suggest a new way of thinking about the spatial organisation of ancient cities. Although there is a great deal of variation in their design and amenities, there are also 

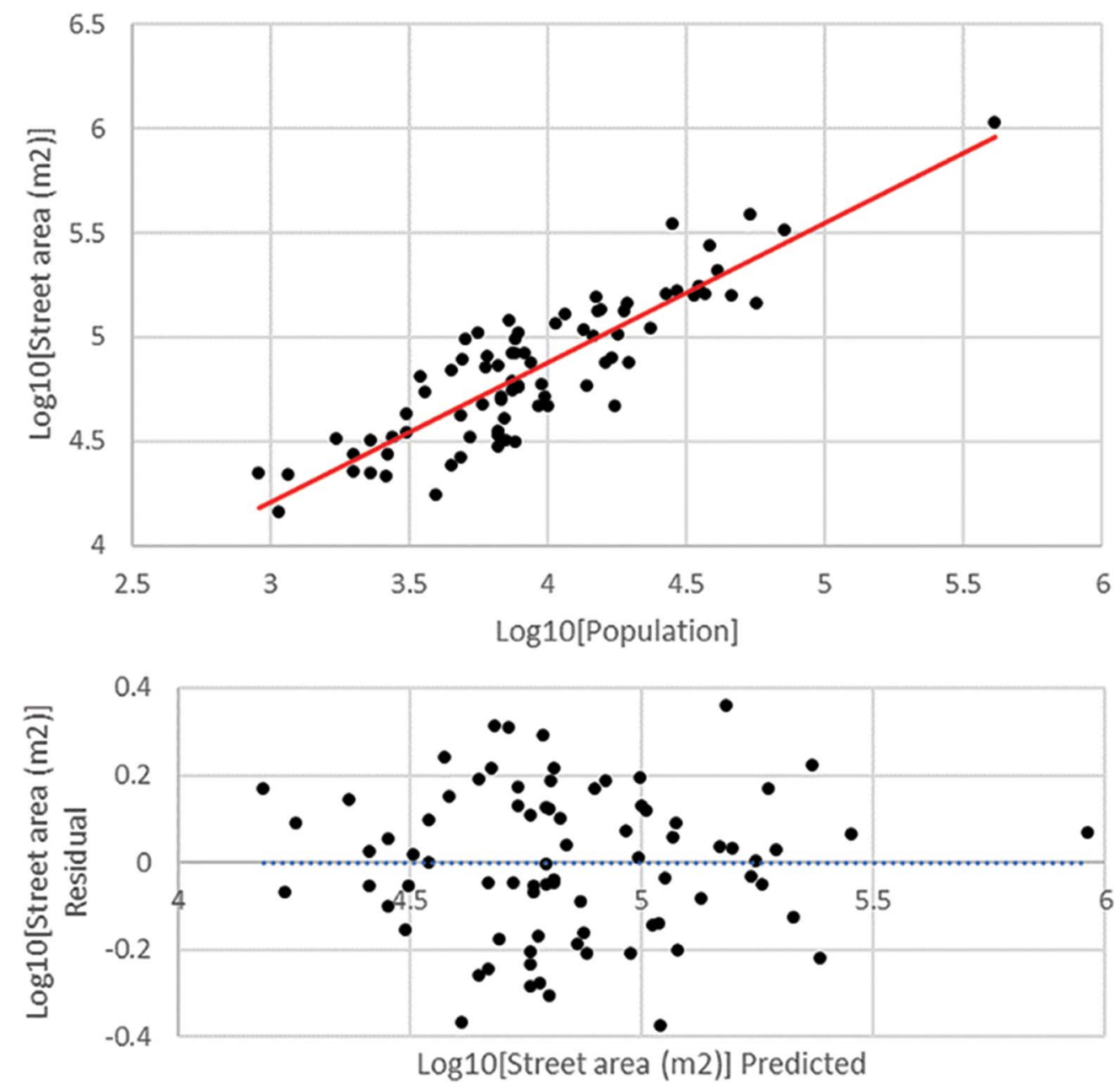

Figure 6. The relationship between population and street network area and the distribution of residuals from the fit-line; it is not possible to reject the null hypothesis that the residuals are normally distributed (Shapiro-Wilk $P=$ 0.576) (figure by J. Hanson).

strong relationships between their population sizes and several measures of their urban forms. This is remarkable when considering the extreme heterogeneity that we would expect in the visible traits of settlements resulting from the interplay of different factors over time-for example, specific interventions in their urban form, expansion or contraction, geographically or historically contingent constraints and random shocks—as well as the varying amount of archaeological information we have about these settlements. This is important, as it indicates that ancient cities were capable of taking advantage of economies of scale through their use of infrastructure, complementing the specialisation and diversification effects identified elsewhere (Hanson et al. 2017). These results also suggest 
Table 1. The relationships between population and various measures of urban form in cities in the Roman Empire.

\begin{tabular}{lccccc}
\hline Dependent variable & $\begin{array}{c}\text { Number } \\
\text { of cases }\end{array}$ & $\begin{array}{c}\text { Exponent } \\
(\mathbf{9 5 \% ~ C . I . )}\end{array}$ & $\begin{array}{c}\text { Pre-factor } \\
(\mathbf{9 5 \% ~ C . I . )}\end{array}$ & $\mathbf{R}^{2}$ & Significance \\
\hline $\begin{array}{l}\text { Inhabited area }(\mathrm{ha})^{*} \\
\begin{array}{l}\text { Forum/agora area } \\
\left(\mathrm{m}^{2}\right)\end{array}\end{array}$ & 53 & $0.65(0.59-0.72)$ & $0.15(0.08-0.27)$ & 0.88 & $<0.0001$ \\
$\begin{array}{l}\text { Street area }\left(\mathrm{m}^{2}\right) \\
\text { Street length }(\mathrm{m})\end{array}$ & 80 & $0.67(0.57-0.77)$ & $9.15(3.59-23.28)$ & 0.68 & $<0.0001$ \\
Street width $(\mathrm{m})$ & 80 & $0.67(0.59-0.75)$ & $158.63(74.67-336.99)$ & 0.77 & $<0.0001$ \\
Block area $\left(\mathrm{m}^{2}\right)$ & 80 & $0.16(0.09-0.24)$ & $2.03(1.04-3.94)$ & 0.20 & $<0.0001$ \\
& 80 & $0.47(0.32-0.61)$ & $180.55(46.92-694.73)$ & 0.33 & $<0.0001$ \\
\hline
\end{tabular}

* Results from Hanson \& Ortman (2017: tab. 5).

that a range of settlements functioned in more or less the same manner, regardless of whether they were formally laid out, developed organically or were a combination of the two.

The results also reveal some important aspects of fora and agorae, in that they support the expectation that these spaces were used more intensively as cities grew, in turn suggesting that fora and agorae must have been used for a range of functions. This is consistent with studies of plazas in the New World and elsewhere (Ossa et al. 2017). Furthermore, these results also highlight a key difference in the operation of street networks in ancient and modern cities. Specifically, our results suggest that, in ancient cities, a constant fraction of the built-up area was set aside for street networks to facilitate the movement of people and goods within the settlement. In contrast, the typical pattern in modern cities is for a slightly greater fraction of the built-up area to be set aside for street networks as population grows. As a result, ancient cities would have had to increase the rate at which traffic could flow (i.e. the flux of transportation) through their infrastructure at a faster rate with population growth than is typical today. In this scenario, the population grows more rapidly than the street area, leading to increasing congestion in the use of the street network (interestingly, this is also a feature of ancient accounts of urban life, such as Juvenal's Satires (especially Satire 3). This suggests that street networks were quite congested in ancient cities relative to the modern experience. These discrepancies are almost certainly explained by differences in construction and transportation technologies, such as variations in the heights of buildings and the maximum distance a pedestrian $v$ s motorised transport can travel in a reasonable length of time. This suggests some interesting directions for future research, which may yield important insights for modern urban planners.

The approach employed in this article could also be used to probe assumptions about the infrastructural requirements of specific ancient sites. A good example is Lepcis Magna, which was excluded from the analysis above, as evidence is only available for a portion of the site. Based on the area enclosed by the later walls, we would expect the site to have had approximately 150000 inhabitants (Hanson 2016; Hanson \& Ortman 2017). There is only 
evidence, however, for around 0.9 ha of communal space at Lepcis Magna, including both an old and a new forum. Thus, the site would appear to be an outlier from the relationships shown in Figure 5. Some scholars have argued that the new forum may originally have been intended to take the form of a double piazza, with the per capita as the central monument—as evidenced by the large area of buildings to the north-east of the main street that were demolished ready for construction work (Di Vita 1979; Laurence et al. 2011: 128-29). This new forum design, however, seems to have been abandoned (or deferred) before the work was completed (although the relevant area has never been excavated to confirm details). As reconstructions of the putative double forum at Lepcis Magna are more in accordance with the overall scaling relationship, this draws our attention to an aspect of the site that might have otherwise remained unrecognised, that is, the extent to which it was underserved in terms of the provision of communal space by these design changes. This suggests that we can use the residuals of the relationships between the populations and the various attributes of sites to identify cases where cities were the result of exceptional circumstances, or where we are missing data. Thus, the kind of analysis we have used here may contribute to improving the overall documentation and interpretation of ancient cities.

\section{Conclusions}

In this article, we have offered a formal model of the relationship between the estimated populations of sites and the infrastructure designed to allow individuals to interact and exchange information, goods and services. We have tested the applicability of this model to the ancient world by concentrating on three basic measures of urban form analogous to modern infrastructure: fora and agorae, street networks and city blocks. The results demonstrate that there are strong relationships between the population size of ancient settlements and various aspects of their urban form, which are consistent with the expectations of settlement-scaling theory.

We have argued that these models offer a new way of thinking about the design and amenities of ancient settlements, which suggest that various aspects of their urban form are not random and, moreover, can be understood as the direct result of interactions between individuals in the context of the built environment. This suggests that, despite wide variation in form, settlements can still be characterised by a few simple relationships, and that concentrating on these may help us to account for the variation that remains after taking population size into account. In doing so, we hope to have advocated for a more systematic approach to the investigation of ancient settlements that is capable of not only incorporating sites with divergent experiences into the same model, but also of exposing their similarities and differences.

\section{Acknowledgements}

We would like to thank the anonymous reviewers for their comments. Elements of this research were supported by a grant from the James S. McDonnell Foundation (\#220020438). 


\section{Supplementary material}

To view supplementary material for this article, please visit https://doi.org/10.15184/aqy. 2018.192

\section{References}

Angel, S., J. Parent, D.L. Civco \& A.M. Blei (ed.). 2012. An atlas of urban expansion. Cambridge (MA): Lincoln Institute of Land Policy.

Batтy, M. 2013. The new science of cities. Cambridge (MA): MIT Press. https://doi.org/10.7551/mitpress/9399.001.0001

Bettencourt, L.M.A. 2013. The origins of scaling in cities. Science 340: 1438-41. https://doi.org/10.1126/science.1235823

Bettencourt, L.M.A. \& G.B. West. 2010. A unified theory of urban living. Nature 467: 912-13. https://doi.org/10.1038/467912a

Bettencourt, L.M.A., J. Lobo, D. Helbing, C. Kühnert \& G.B. West. 2007. Growth, innovation, scaling, and the pace of life in cities. Proceedings of the National Academy of Sciences of the USA 104: 7301-306. https://doi.org/10.1073/pnas.0610172104

Burns, R. 2017. The origins of the colonnaded streets in the cities of the Roman East. Oxford: Oxford University Press.

Carandini, A., P. Carafa \& A. Campbell HaLavais. 2017. The atlas of ancient Rome: biography and portraits of the city. Princeton (NJ): Princeton University Press.

Cesaretti, R., J. Lobo, L.M.A. Bettencourt, S. Ortman \& M.E. Smith. 2016. Population-area relationship for Medieval European cities. PLoS ONE 11(10): e0162678. https://doi.org/10.1371/journal.pone.0162678

Di VITA, A. 1979. Il progetto originario del forum novum Severianum a Leptis Magna. 150-Jahr-Feier Deutsches archäelogisches Institut Rom, $\operatorname{MDAI}(R)$ 25: 84-100.

Dobisns, J.J. \& P.W. Foss (ed.). 2005. The world of Pompeii. London: Routledge.

Fujita, M., P.R. Krugman \& A.J. Venables. 2001. The spatial economy: cities, regions, and international trade. Cambridge (MA): MIT Press.

Gros, P. 1996. L'architecture romaine: du début du IIIe siècle av. J.-C. à la fin du Haut-Empire. Paris: Picard.

Hanson, J.W. 2016. An urban geography of the Roman world, 100 BC to AD 300. Oxford: Archaeopress.
Hanson, J.W. \& S.G. Ortman. 2017. A systematic method for estimating the populations of Greek and Roman settlements. Journal of Roman Archaeology 30: 301-24. https://doi.org/10.1017/S1047759400074134

Hanson, J.W., S.G. Ortman \& J. Lobo. 2017. Urbanism and the division of labour in the Roman Empire. Journal of the Royal Society Interface 14(136): 1-12. https://doi.org/10.1098/rsif.2017.0367

КозтоF, S. 1991. The city shaped: urban patterns and meanings through history. New York: Thames \& Hudson.

- 1992. The city assembled: elements of urban form through history. New York: Thames \& Hudson.

Laurence, R., S. Esmonde Cleary \& G. SEARs. 2011. The city in the Roman West, c. 250 $B C-$ c. $A D$ 250. Cambridge: Cambridge University Press. https://doi.org/10.1017/CBO9780511975882

Louf, R. \& M. Barthelemy. 2014. A typology of street patterns. Journal of the Royal Society Interface 11(101): $1-7$. https://doi.org/10.1098/rsif.2014.0924

MacDonald, W.L. 1986. The architecture of the Roman Empire. London: Yale University Press.

Mandich, M.J. 2016. Urban scaling and the growth of Rome, in S. Gonzalez Sanchez, G. Savani, E. Zampieri, T.J. Derrick \& M.J. Mandich (ed.) TRAC 2015: proceedings of the 25 Annual Theoretical Roman Archaeology Conference: 188-203. Oxford: Oxbow.

McKenzie, J. 2007. The architecture of Alexandria and Egypt. New Haven (CT): Yale University Press.

Ortman, S.G., A.H.F. Cabaniss, J.O. Sturm $\&$ L.M.A. BetTenCourt. 2014. The pre-history of urban scaling. PLoS ONE 9: e8790. https://doi.org/10.1371/journal.pone. 0087902

Ossa, A., M.E. Sмiтн \& J. Loвo. 2017. The size of plazas in Mesoamerican cities and towns: a quantitative analysis. Latin American Antiquity 28: 457-75. https://doi.org/10.1017/laq.2017.49

(C) Antiquity Publications Ltd, 2019 
Poenler, E. 2017. The traffic systems of Pompeii. Oxford: Oxford University Press.

Rowland, I.D. \& T.N. Howe. 1999. Vitruvius: ten books on architecture. Cambridge: Cambridge University Press.

Sмiтh, M.E. 2007. Form and meaning in the earliest cities: a new approach to ancient urban planning. Journal of Planning History 6: 3-47. https://doi.org/10.1177/1538513206293713
Strano, E., V. Nicosia, V. Latora, S. Porta \& M. BARTHELEMy. 2012. Elementary processes governing the evolution of road networks. Scientific Reports 2(296): 1-8. https://doi.org/10.1038/srep00296

Ward-Perkins, J.B. 1981. Roman imperial architecture. London: Penguin.

Zuiderhoek, A. 2016. The ancient city. Cambridge: Cambridge University Press.

Received: 15 March 2018; Revised: 27 July 2018; Accepted: 22 August 2018

(C) Antiquity Publications Ltd, 2019 